\title{
COMPARISON STUDY OF SPHERICAL AND MULTI-SPHERICAL PARTICLES UNDER CYCLIC UNIAXIAL COMPRESSION
}

\author{
Liudas Tumonis ${ }^{1}$, Rimantas Kačianauskas $^{2}$, Arnoldas Norkus ${ }^{3}$, Daiva Žilioniené ${ }^{4}$ \\ ${ }^{1}$ Laboratory of Combustion Processes, Lithuanian Energetics Institute, \\ Breslaujos g. 3, 44403 Kaunas, Lithuania \\ ${ }^{2}$ Department of Strength of Materials, Vilnius Gediminas Technical University, \\ Saulètekio al. 11, 10223 Vilnius, Lithuania \\ ${ }^{3}$ Department of Geotechnical Engineering, Vilnius Gediminas Technical University, \\ Saulètekio al. 11, 10223 Vilnius, Lithuania \\ ${ }^{4}$ Department of Roads, Vilnius Gediminas Technical University, Sauletekio al. 11, 10223 Vilnius, Lithuania \\ E-mails: ${ }^{1}$ Liudas.Tumonis@vgtu.lt (corresponding author); ${ }^{2}$ Rimantas.Kacianauskas@vgtu.lt; \\ 33Arnoldas.Norkus@vgtu.lt; ${ }^{4}$ daizil@vgtu.lt \\ Received 23 Feb. 2012; accepted 11 May 2012
}

\begin{abstract}
Numerical simulation of cyclic compression of granular material by performing oedometric test has been performed. Discrete Element Method (DEM) has been employed for simulation. A comparison study has aimed to examine the differences in macroscopic behaviour of material discretized by spherical (S) and non-spherical shape models of a particle. During the study, microscopic data of sand from Klaipeda were used for modelling the shape of particles. The nonspherical particles were described by multi-spherical (MS) models retaining distributions for size and aspect ratios. Two DE models of tested specimens were developed and the deformation behaviour under cyclic uniaxial compression was simulated numerically by applying the commercial EDEM code.

The variation of the oedometric elasticity modulus was investigated and influence of particle shape on void ratio changes was demonstrated. It was clearly shown that application of S particles is much more sensitive to rearrangement of particles during densification DEM. Simulations illustrated that the elasticity modulus of material corresponding to MS particles is approximately 1.9 times larger comparing with material corresponding to $\mathrm{S}$ particles. Therefore, one must improve the magnitude of elasticity modulus by introducing a respective correction factor.
\end{abstract}

Keywords: oedometer test simulation, void ratio, elasticity modulus, cyclic compression, discrete element method, spherical and multi-spherical particles.

\section{Introduction}

Sands represent a particular and important example of soils. Traditionally, they are the subject extensively considered in many areas of the civil and structural engineering. The knowledge and the proper understanding of their mechanical behaviour are of major importance in the construction of foundations of structures, geotechnical facilities and in the processing of building materials (Amšiejus et al. 2009; Amšiejus, Dirgelienè 2007).

From the point of view of mechanics, sands are highly inhomogeneous. They present a composition of grains and may be treated as granular solids. In whatever form they are used, granular materials are important in almost all areas of science and technology. Therefore, a common framework used for granular materials may also be applicable to sands.

Recently the behaviour of granular solids has been extensively investigated by applying analytical, experimental and numerical methods. Macroscopically, the granular solids may be considered in various forms of continuum theories (Jiang, Liu 2007a, 2009; Zalewski 2010). Transitional micro-macro approaches were considered by Luding et al. (2001) and Chen and Lan (2009). The issues related to granular models of sands were reviewed by Jiang and Liu (2007b).

Despite the huge effort and progress in numerical analysis, the adequacy of theoretical models of the granular solids to actual behaviour is still problematic. The continuum approach used in a framework of the classical mechanics does not provide information on the microproperties at the scale of an individual grain. Therefore, an application of the continuum-based methods, being attractive for relative small computational efforts despite their wide use even also in soil mechanics, is not suitable aiming for adequate representation of the discrete nature of soils.

The experimental investigation on interaction of particles is somewhat costly and time consuming; therefore an application of numerical simulations is frequently used to replace the macroscopic physical experiments. Discrete Element Method (DEM) was acknowledged as a powerful tool for simulating the particulate matter after 
the publication of the work by Cundall and Strack (1979). The DEM concept offers a unique approach capturing the various particle shapes and physical models by a discrete set of quantities. The basics of DEM and important details were described in books and review papers of Allen and Tildesley (1987), Pöschel et al. (2004), Džiugys and Peters (2001), Kruggel-Emden et al. (2007), Zhu et al. (2007, 2008).

The discrete concept and the available commercial DEM codes such as EDEM (see DEM Solutions 2009), PFC3D (Itasca 2003) and the numerous non-commercial research codes have turned DEM into an attractive research tool.

At the same time, the computational capability limiting a number of particles to be employed for simulations, remains the main disadvantage of the DEM technique, so far. The simulation techniques and software issues were discussed by Raji and Favier (2004), Kačianauskas et al. (2010).

The particle shape in concert with other properties is an important factor contributing to results and efficiency of DEM simulations. The particle shapes possess a great diversity but numerical techniques mostly deal with spherical (S) surfaces. A general so called multi-spherical (MS) approach for the representation of non-spherical particles by rigidly connected multi-spheres or clumps, was recently explored in the Discrete Element (DEM) and applied to various shapes (Garcia et al. 2009; Ferellec, McDowell 2010). The contact detection efficiency and simplicity of implementation by using sphere-to-sphere contact are the main advantages of the multi-sphere model.

A systematic study of MS application to a regular smooth shape such as an ellipsoid proving a suitability of them was presented by Markauskas et al. (2010). An approximation of the non-smooth spherical particle by applying the MS models was considered by KruggelEmden et al. (2008), Höhner et al. (2011), Markauskas and Kacianauskas (2011).

There are some other more complicated approaches to construction of complex shapes of a particle from spheres, cylinders and flats (Langston et al. 2004; Pournin et al. 2005; Tijskens, Rioual 2008). The method for generation of a particle shape by applying the solid bridge bond model was described by Antonyuk et al. (2011).

Some applications of the DEM to modelling of dry sands may be emphasised. They comprise behaviour of sand in technological processes such as filling and compaction of sand by vibration (Rojek et al. 2005) or simulation of various tests. The above mentioned investigations are considered by applying various shapes of specimens and particles. The common feature of the above mentioned instigations is monotonic loading.

In many cases, three-dimensional sample in a form of the rectangular parallelepiped was examined. The effect of the use of flat boundaries during onedimensional compression was considered by Marketos and Bolton (2010). A cuboidal sample to simulate the biaxial compression with rigid walls was studied by Yan et al. (2009). DEM simulations of the standard oedomet- ric tests with cylindrical samples were presented by Oquendo et al. (2009), Amšiejus et al. (2010).

Most of investigations deal with spherical (S) particles. The spherical shape is, however, rather rough idealization to represent the real granular material elements such as sand grains. The real sand particle is irregular and involves more complex intergranular interactions as that identified between spheres. A comparison of simulation results by using spherical particles and clumps were given by Yan et al. (2009). The comparison of simulation results with laboratory results show that the results obtained with clump particle samples are more accurate when compared with the results obtained with spherical particles.

The paper presents a numerical investigation of the behaviour of particulate solid under uniaxial cyclic compression. The problem is considered by DEM simulations of the oedometric test. Thereby, two sets of spherical and non-spherical particles are studied for the sake of comparison.

The paper is organised as follows: the DEM methodology is presented in Section 2; the basic data is given in Section 3; simulation approach comprising generation of the specimen and simulation of mechanical behaviour are given in Section 4; simulation results and the discussion are given in Section 5; and conclusions are presented in Section 6.

\section{DEM methodology}

The DEM methodology considered in this paper was used for simulating the dynamic behaviour of non-cohesive frictional viscoelastic particles. Each of the particles is regarded as a deformable body with a specified shape and material properties. During the rearrangement/movement of particles, they impact each other and undergo deformations. The motion of the particle, discretized as a rigid body and described in a framework of classical mechanics, naturally consists of translational and rotational motions, respectively. The position of the arbitrary particle is tracked by motion of the particle's centre. More definitely, the arbitrary particle $i$ in global coordinates is defined by its position vector $\mathbf{X}_{\boldsymbol{i}}=\left\{X_{i 1}, X_{i 2}, X_{i 3}\right\}^{\mathrm{T}}$. Consequently, the translational behaviour of the arbitrary particle $i$ in time $t$ is characterised by a small number of global parameters, namely: positions $\mathbf{X}_{i}(t)$, velocities $\dot{\mathbf{X}}_{\boldsymbol{i}}(t)$ and accelerations $\ddot{\mathbf{X}}_{\boldsymbol{i}}(t)$ of the mass centre, the resultant force vector $\mathbf{F}_{i}(t)$ acting on the particle. The particle $i$ is moving according to the Newton's second law and is written as:

$$
m_{i} \ddot{\mathbf{X}}_{i}(t)=\mathbf{F}_{i}(t) .
$$

Equations describing the rotational motion, or the Euler equations, are derived by assuming a conservation of an angular momentum for the particle $i$ and may be considered as well. The rotation is governed by three independent rotational degrees of freedom defined by vector $\boldsymbol{\Theta}_{i}(t)$. Conventionally, the rotational degrees of freedom are defined by the angles of rotation. It is usual, 
however, to deal with the explicitly tracked angular velocities of the particle defined by the vector $\boldsymbol{\omega}_{i}(t)$. Angular velocities are related to $\boldsymbol{\Theta}_{i}(t)$ by the nonlinear pathdependent rotational Jacobi matrix. Finally, the Euler equations for rotational motion of arbitrary shaped particle are presented by:

$$
\left[\mathbf{I}_{i}\right] \dot{\boldsymbol{\omega}}_{i}(t)+\left[\tilde{\boldsymbol{\omega}}_{i}(t)\right]^{\mathrm{T}}\left[\mathbf{I}_{i}\right] \boldsymbol{\omega}_{i}(t)=\mathbf{T}_{i}(t)
$$

where: matrix $\left[\mathbf{I}_{i}\right]$ presents the inertia tensor; the matrix $\left[\tilde{\boldsymbol{\omega}}_{i}(t)\right]$ is composed by the components of the vector $\boldsymbol{\omega}_{i}(t)$, while $\mathbf{T}_{i}(t)$ is a vector of the external torque with respect to the particle mass centre.

For the spherical particles, the inertia tensor is diagonal and the axial inertia moments are equal and defined by the single parameter $I_{i}$. Therefore, the orientation in space is not important and the equations of rotation (2) then can be rewritten in the simpler form:

$$
I_{i} \dot{\mathbf{\omega}}_{i}(t)=\mathbf{T}_{i}(t)
$$

In framework of the current investigation, the force vector $\mathbf{F}_{i}$ in Eq. (1) and the torque vector $\mathbf{T}_{i}$ in Eq. (2) or (3) present the sum of gravity and contact forces and torques, which act on the particle $i$, respectively. Therewith, the evaluation of the contact force and that of the torque components is essential part of the DEM methodo$\operatorname{logy}$.

This methodology is based on the contact between spheres and is comprehensively described in Cundall and Strack (1979), Džiugys and Peters (2001), Zhu et al. (2007). The main approach assumes that the force between two particles $i$ and $j$ may be decomposed into normal and tangential components $\mathbf{F}_{i j}=\mathbf{F}_{i j}^{n}+\mathbf{F}_{i j}^{t}$. In the case of viscoelastic dry frictional contact, the inter-particle contact model considers a combination of elasticity, damping and friction force effects. In the context of DEM, the nonspherical particles will be shaped by multi-sphere (MS) models or clumps (Favier et al. 1999; Raji, Favier 2004). Here, a continuous particle is simulated by a composition of connected spheres. Its main advantages are contact detection efficiency and simplicity of implementation using the methodology for sphere-to-sphere contacts.

However, two distinct features should be taken into account. Firstly, not only a single conventional contact occurs between the interacting particles, but the multiple contacts between the constituent spherical particles may occur. In this case, the contacting points may be attributed to particular sub-spheres. Secondly, directions of contact forces are defined with respect to the separate sphere but not with respect to the centre of a particle. Consequently, contact forces and torques obtained for sub-spheres have to be transformed to the centre of the complex particle.

\section{Particle data}

The particle data required in the DEM simulations comprise their sizes, shapes and the actual physical and mechanical properties. A proper evaluation of them is a very important but rather complicated task. Moreover, all natural geological materials including sands are greatly diverse. Sand grains from Klaipeda (characteristic Baltic see-shore sand) were chosen for modelling of particles in our investigation.

The character of grain composition is illustrated by the micrograph presented as Fig. 1. The picture was taken by the optical microscope "Nikon Ellipse 50i Pol".

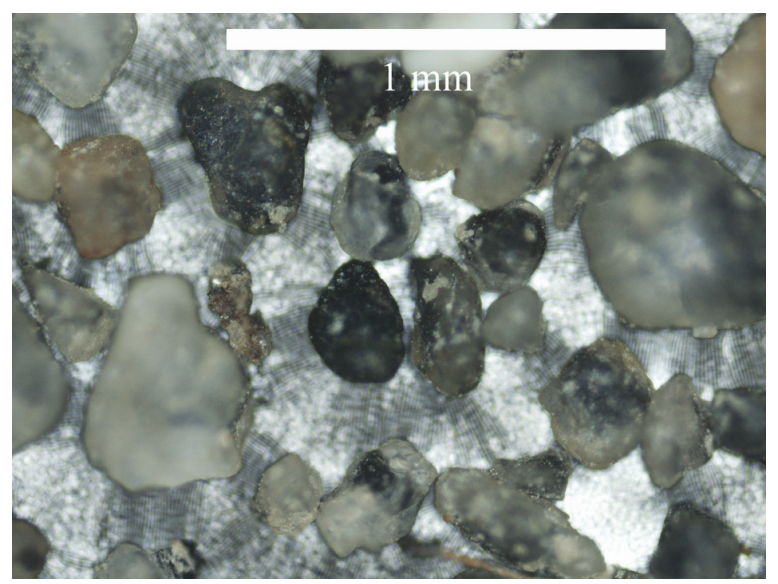

Fig. 1. Micrograph of real sand particles

Microscopic graph illustrates the character of particles. The average maximal diameter $\mathrm{d}$ of particles varies in the range of $0.2 \mathrm{~mm}$ and $0.50 \mathrm{~mm}$. Detailed distribution of sand composition was evaluated via standard granulometric testing procedures (see ISO 14688-2:2004). Cumulative size distribution of sand grains is presented in Fig. 2. The graph shows fraction $\Phi$ of the mass of sand which contains particles of a certain maximal size.

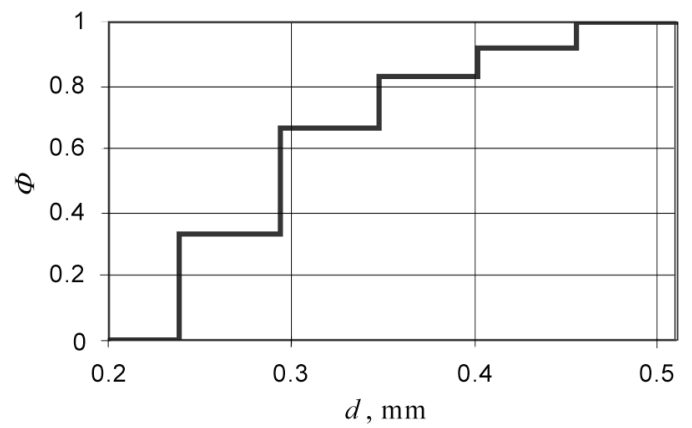

Fig. 2. Cumulative size distribution of sand grains by the maximal diameter

The above presented size distribution of particles was employed for generation of particles used for numerical analysis of compaction. Two types of particle shapes, i.e. spherical and non-spherical, were considered for investigation purposes, and two sets of particles were generated numerically. Each of the two selected shapes is characterised by its size $d_{\max }$ according to specified distribution of the particle size. For spheres, the size stands simply for their diameter $d_{\max }=2 R$.

When considering the shape of particles, it could be observed that the grain surface is of abrade smooth character. Twelve typical particle shapes were selected from 
the micrograph for numerical calculations. Geometry of particles is characterised by one of the most common shape factors, i.e. the aspect ratio. The aspect ratio is the ratio of maximal to minimal particle diameters $K_{f}=d_{\max } / d_{\min }$. It varies within bounds of 1.11 and 1.92. The distribution $f$ of the aspect ratio by mass of examined grains is presented in Fig. 3.

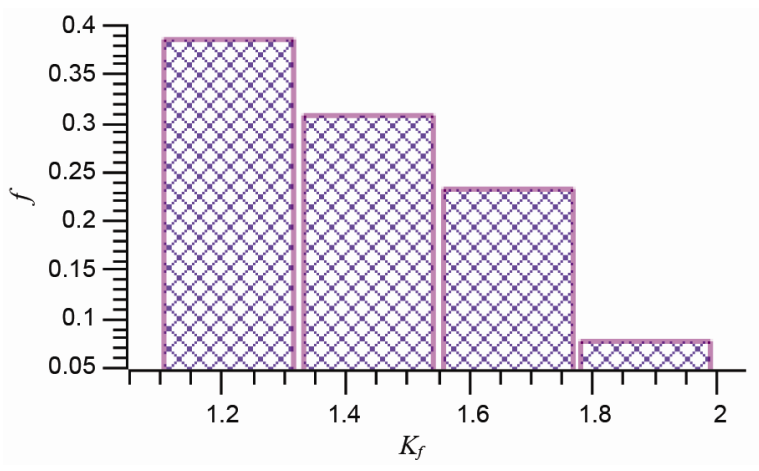

Fig. 3. Distribution of the aspect ratio of sand grains

Referring to the real particle shapes, the multispherical (MS) approximation appeared to be the most suitable particle model for irregular locally concaved particle shape. Twelve microscopic images were used to generate multi-sphere models. Aspect ratios $K_{f}$ were specified to reflect the shape variation of particles in accordance to distribution as shown in Fig. 3. The result twelve generated models of the MS particles without any symmetry - is presented in Fig. 4. Each of the particle was generated from a number of spheres ranging between 6 and 8. Distribution of the aspect ratios of the MS particles is the same as the experimentally measured distribution of twelve real particles (Fig. 3).

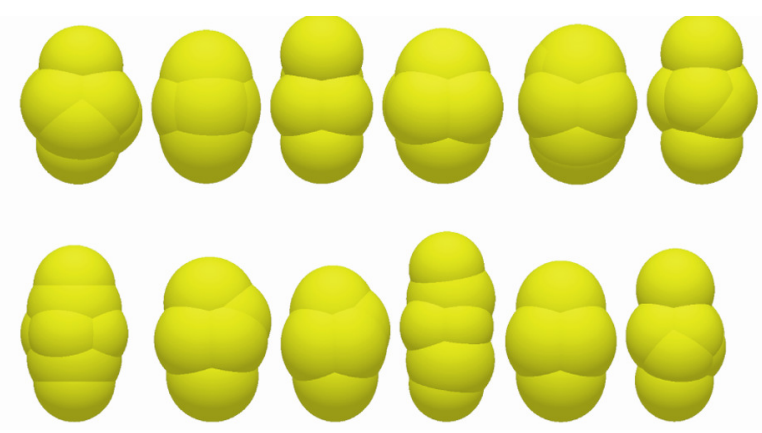

Fig. 4. Twelve models of MS particles of different sizes and aspect ratios

The physical elasticity properties of the particle $i$ are defined by the elasticity modulus $E_{p}$, the Poisson's ratio $v$ and the shear modulus $G$, while the inter-particle contact is redefined by stiffness coefficients $k_{i j}^{n}$ and $k_{i j}^{t}$.

Elasticity properties of particles play the decisive role in a compression experiment. It is obvious, that extremely high values of elasticity modulus of silica grains $E_{p}$ yield very small time increment $\Delta t \sim \sqrt{\rho_{p} / E_{p}}$ and, as a consequence, long lasting computations.
Various measures could be undertaken to reduce computation expenses. The most useful approach is the scaling of various parameters. Similarity of physical systems was comprehensively discussed by Pőschel et al. (2001). Generally, the scaling of data requires a rescaling of all results. It is easy to persuade that a reduction of $E_{p}$ by factor $\alpha$ allows increasing the time step by the factor $\sqrt{\alpha}$. Moreover, it was proofed by Kruggel-Emden et al. (2010) that when compressing the particles by relatively small rates, dynamic effects are of a minor importance, therefore, the simple rescaling of pressure variables is sufficient. In conclusion, linearity is a necessary scaling condition. This condition is not sufficient for evaluation of absolute values but it is sufficient for relative comparison of two different models.

In the light of the above discussion, the actual elasticity modulus $E_{p}=78 \mathrm{GPa}$ was scaled down by the factor $\alpha=16900$ and the value $E_{p}^{\prime}=4.62 \mathrm{MPa}$ was employed in simulations.

Another important property is friction. The influence of friction for granular materials is reviewed by Zhu et al. (2007). It is obvious, that because of a scattering of experimental results only a crude approximation of the friction for sand is available (Rojek et al. 2005; Oquendo et al. 2009). In the current investigation, the single friction coefficient between the particle and wall (microscopic scale) and between particles $\mu=\mu_{w}=\mu_{g r}$, was chosen, while a relatively small magnitude $\mu=0.3$ was taken to respond the smoothness of particles.

Role of damping in compaction is merely of a simulation rather than the physical character. In our simulations, the viscous damping effect was evaluated by a coefficient of restitution. An average value of the normal grain-wall coefficient of restitution $c^{n}=0.5$ was obtained by the grain-bed collision experiments performed in the wind tunnel (Wang et al. 2008). The tangential damping and rolling friction were neglected.

The summarised data of values describing the particle physical properties, applied in the DEM simulations, are summarised in Table 1.

Table 1. Material properties of particles

\begin{tabular}{l|c|c|c}
\hline \multicolumn{1}{c|}{ Quantity } & Symbol & Unit & Value \\
\hline Density & $\rho$ & $\mathrm{kg} / \mathrm{m}^{3}$ & 2650 \\
\hline $\begin{array}{l}\text { Elasticity modulus of } \\
\text { particle }\end{array}$ & $E_{p}$ & $\mathrm{MPa}$ & 78000 \\
$\begin{array}{l}\text { Elasticity modulus in } \\
\text { simulation }\end{array}$ & $E_{p}^{\prime}=E_{p} / 16900$ & $\mathrm{MPa}$ & 4.61 \\
\hline $\begin{array}{l}\text { Poisson's ratio } \\
\text { Tangential friction } \\
\text { coefficient }\end{array}$ & $v$ & - & 0.17 \\
\hline $\begin{array}{l}\text { Normal coefficient of } \\
\text { restitution }\end{array}$ & $c^{n}$ & - & 0.3 \\
\hline
\end{tabular}

\section{Simulation approach and generation of specimens}

Deformation behaviour of particulate solid under cyclic uniaxial oedometric compression was considered numerically by applying the DEM. Therewith, the oedometric device presents a metallic cylinder being fixed to a rigid 
base. In real experiments, the internal volume of the cylinder, aimed to be filled by tested sample material, is of $H=35 \mathrm{~mm}$ height and $D=70 \mathrm{~mm}$ in diameter. One must note that performing numerical experiments with original size of the oedometer is rather difficult and impractical due to the computational limitations. For this reason, the actual size of the oedometer was reduced by scaling factor equal to seven. Thus, the computational model of the cylinder was limited by $H=5 \mathrm{~mm}$ and $D=10 \mathrm{~mm}$. The scaling allows executing the adequate to actual behaviour numerical experiments with originally sized particles.

The series of numerical experiments were performed to investigate the behaviour of particles under the cyclic compression. The state of particles during the compaction process was obtained by an integration of the Equations of motion (1-3). The current DEM simulations were performed by applying the EDEM 2.2.1 Academic code (DEM solutions 2009).

Numerical simulation was naturally divided into two stages: the generation of the initial state of particles or packing stage, and of the compression stage.

For conducting the real laboratory experiment, the specimen always retains its natural properties which should be satisfied by initial conditions of the simulated material. Generation of the initial state of particles, i.e. prescribing the location of particles in the cylinder is subjected to the specific requirements. Consequently, numerical generation of the specimen for DEM simulation is the separate problem that requires a considerable effort.

The generation of the initial conditions of particles is treated as the packing problem. There are several methods to realize the packing process for satisfying various requirements. The packing problem was comprehensively discussed in review papers by Zhu et al. (2007), and Belevicius et al. (2011). In our considered case, an initial state is generated by the particle's deposition. A set of generated particles is randomly located above the cylinder and allowed to fall freely due to gravity forces.

The explicit integration scheme with a constant time step $\Delta t$ was applied for numerical integration of the equations of motion. The magnitude of $\Delta t$ is chosen to be a smaller than the Rayleigh time step, that being calculated by EDEM. The total time of filling $t_{f}=0.18 \mathrm{~s}$ is continued to stabilise of the particles motion after the filling.

The process of filling was controlled by a monitoring the evolution of the volume of particulate and was interrupted when it reached the volume of the devise.

Finally, two sets consisting $N_{S}=10428$ number of S particles and of $N_{M S}=24521$ number of MS particles, respectively, were generated for investigative purposes.

An important parameter of packing is a void ratio. The void ratio is characterised by a void ratio $e$ obtained as the ratio of volume of voids to the volume of grains $V_{g r}$, namely:

$$
e(t)=\frac{V_{s o l}(t)-V_{g r}}{V_{g r}},
$$

where $V_{\text {sol }}(t)$ is the time varying volume occupied by the solid material which is measured in the oedometric device.

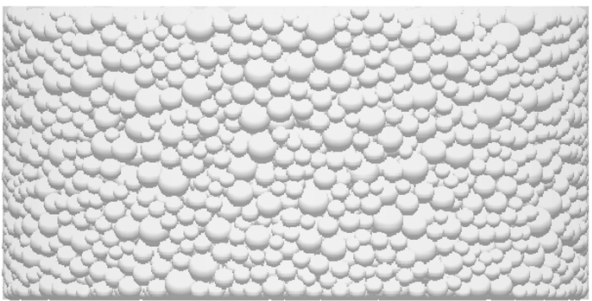

a)

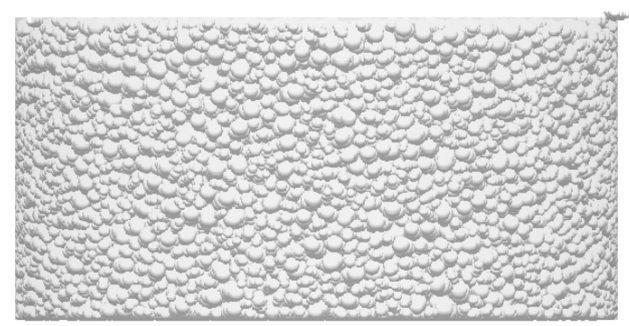

b)

Fig. 5. Non-compressed spherical (a) and multi-spherical (b) particles in oedometer

Evaluation of the void ratio e described in Eq. (4) was realised under the following assumptions:

- the volume of sand grains remains constant $V_{g r}=$ const, i.e. their volume changes due to contact deformation are negligibly small;

- the particles are homogeneous and have constant density $\rho$;

- the macroscopically observed volume changes $V_{\text {sol }}(t)$ of the specimen are induced by a reduction of pores caused by the rearrangement of particles.

As a consequence of the first two assumptions, the volume of grains $V_{g r}=m_{g r} / \rho=$ const could be calculated from the weighted mass of the tested material.

The initial void ratio $e_{0}$ is characterised by its maximal value directly obtained via the Eq. (4), assuming that the entire volume of the cylinder is occupied by the granular solid, i.e. $V_{s o l}=V_{c y l}$.

The most important specimen simulation parameters and characteristics of packings for both $\mathrm{S}$ and MS particle types are summarised in the Table 2. An initial state of the particles is presented in Fig. 5.

Table 2. Data of the generated samples for spherical (S) and multi-spherical (MS)

\begin{tabular}{l|c|c|c|c}
\hline \multirow{2}{*}{-Quantity } & \multirow{2}{*}{ Symbol } & \multirow{2}{*}{ Unit } & \multicolumn{2}{c}{ Value } \\
\cline { 4 - 5 } & & & $\mathrm{S}$ & $\mathrm{MS}$ \\
\hline Min. particle diameter & $d_{\min }$ & $\mathrm{mm}$ & 0.19 & 0.15 \\
\hline Max. particle diameter & $d_{\max }$ & $\mathrm{mm}$ & 0.50 & 0.50 \\
\hline Initial void ratio & $e_{0}$ & - & 0.707 & 0.602 \\
\hline Min. aspect ratio & $K_{f \min }$ & - & 1.0 & 1.11 \\
\hline Max. aspect ratio & $K_{f \max }$ & - & 1.0 & 1.92 \\
\hline Number of particles & $N$ & - & 10428 & 24521 \\
\hline Time step & $\Delta t$ & $\mu \mathrm{s}$ & 0.15 & 0.10 \\
\hline Duration of filling & $t_{f}$ & $\mathrm{~S}$ & 0.28 & 0.28 \\
\hline Duration of compression & $t_{c}$ & $\mathrm{~S}$ & 0.5 & 0.5 \\
\hline
\end{tabular}




\section{Numerical results}

\subsection{Results of compression simulation}

Compression simulation of specimens was performed in the second stage of analysis, i.e. after filling procedures. The loading was treated in a slightly different manner if compared with the real experiment. The time-varying compressing pressure was imposed by moving the upper rigid stamp (upper wall of the cylinder) vertically. Actually, the loading was controlled by the vertical displacement of the stamp $U(t)$. The loading history is characterised by simple sinusoidal half-wave cyclic motion. Each of the loading-unloading cycles is defined with duration time equal to $0.1 \mathrm{~s}$ and up to the maximal amplitude of $U_{\max }=0.15 \mathrm{~mm}$, the value of which was scaled with respect to diameter of the smallest particle. The geometrically specified history of uniaxial cyclic loading in terms of the non-dimensional displacement $u(t)=U(t) / U_{\max }$ is presented in Fig. 6.

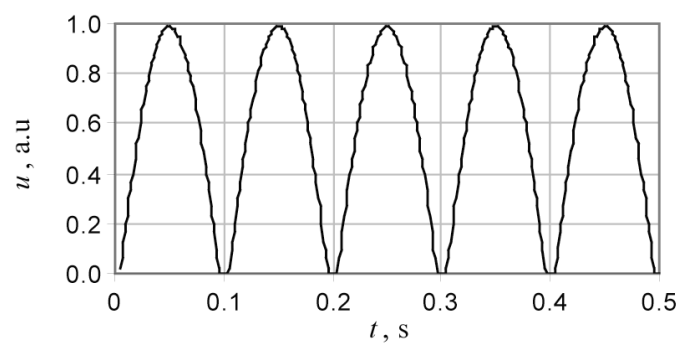

Fig. 6. Time variation of the relative loading displacement

The response of the material is characterised via the resultant pressure $P(t)$ obtained numerically by calculating and averaging contact forces of particles to stamp. Histories of pressures of both specimens in terms of relative variable $p(t)=P(t) / E_{p}^{\prime}$ scaled with respect to particle elasticity modulus $E_{p}^{\prime}=4.62 \mathrm{MPa}$ are presented in Fig. 7. It is obvious that both samples exhibit quite different character of their deformation behaviour.

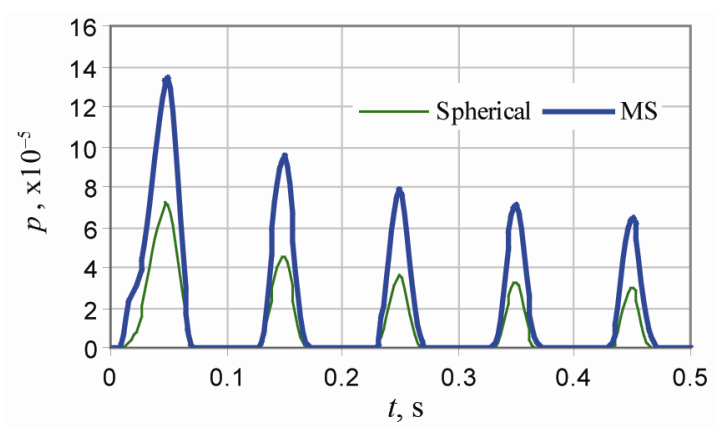

Fig. 7. Cyclic load pressure histories for spherical and MS particles obtained via DEM simulation

The above results serve as the base for an illustration of deformation behaviour.

\subsection{Analysis of deformation behaviour and discussion}

Performance of various tests including the numerical simulations is often dictated by the need of finding representative material properties. It is obvious, that an axial stiffness of the specimen, or elasticity modulus of material is a function of axial stress and deformation measures, therefore it could be extracted from deformation curves. Actually, the secant oedometric modulus $E(t)$ employed in geotechnical engineering can be obtained explicitly by simple expression, reading:

$$
E(t)=\sigma(t) / \varepsilon(t)
$$

The simplest approach to calculate the elasticity modulus would be extracting its values from measured or numerically simulated results. This case would be possible if a proportionality between the simulated normal pressure and the normal stress $p(t)=\sigma(t)$, as well as between the normal displacement and the strain measure $u(t)=\varepsilon(t)$ should be held during an entire loading history.

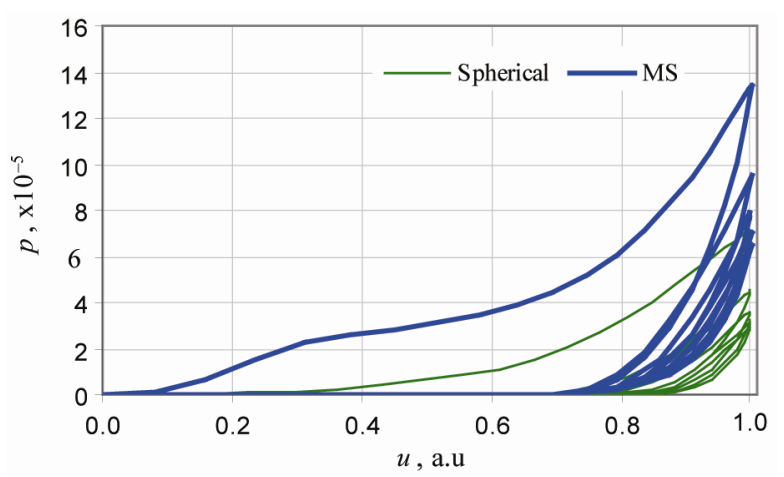

Fig. 8. The simulated pressure-displacement relationships under cyclic loading for different particles

It should be noticed in advance, however, that direct employment of the relationship $p-u$ is not applicable. This typical effect is the well-known problem of oedometric testing. The issue restricted to the monotonic loading was comprehensively discussed by (Marketos, Bolton 2010).

It is easy to convince that the graph shown in Fig. 8 cannot be treated as constitutive relationship.

The issue should be solely explained by inadequacy between the specified external displacement $u(t)$ and internal vertical strain $\varepsilon(t)$. Here, the discrepancy is attributed to rearrangement of voids and densification of material. After each of the loading cycles the volume changes and the same displacement yields different strains, therefore, realistic strain measures regarding densification have to be considered.

An actual value of average normal strain $\varepsilon(t)$ in time should be attributed to an actual geometry of the material. Focusing on the cyclic loading, we restrict ourselves to a discrete variation of the geometry during each of the loading cycle $i$. Thus, an accumulation of the normal strain during the cycle $i$ is defined as a relative shortening $\delta_{\mathrm{i}}=\Delta h_{i}(t) / h_{i 0}$ of an actual material height $h_{i 0}$. Variation of the relative shortening $\delta$ in time for $\mathrm{S}$ and MS particles is illustrated in Fig. 9. 


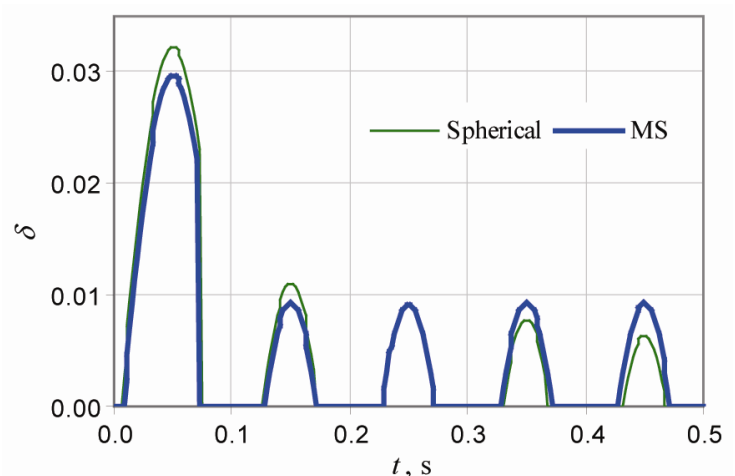

Fig. 9. Variation of the relative elongation $\delta$ in time for $\mathrm{S}$ and MS particles obtained via DEM simulation

Moreover, the deformation of the solid is related to the void ratio $e_{i}(t)$. It is easy to detect that void ratio is expressed via the relative elongation $e_{i}(t)$. In each loading cycle $i$ time variation of the void ratio defined according to Eq. (4) is transformed to the following expression:

$$
e_{i}(t)=e_{i 0}-\varepsilon_{i}(t)\left(1+e_{i 0}\right) .
$$

Now, the strain $\varepsilon$ could be extracted from the above expression and presented as follows:

$$
\varepsilon_{i}(t)=\frac{e_{i 0}-e_{i}(t)}{\left(1+e_{i 0}\right)_{i}} .
$$

The above expression relates the strain to the variation of the void ratio. Regarding the actual configuration in terms of the void ratio, the variation of the average strain, obtained by Eq. (7) with respect to displacement, is given in Fig. 10.

The graph in Fig. 10 illustrates the densification effect. Generally, the varying distance between loading lines indicates changes in the void ratio identified after each of loading cycles.

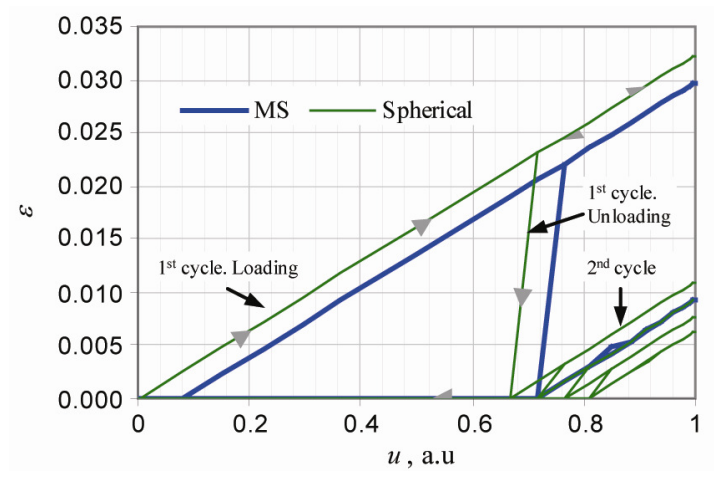

Fig. 10. The strain-displacement relationships for two particle shapes during cyclic loading

Differences in behaviour of particle shapes may be better observed when considering the void ratio changes. The graphs of void ratio versus pressure are presented in Fig. 11.

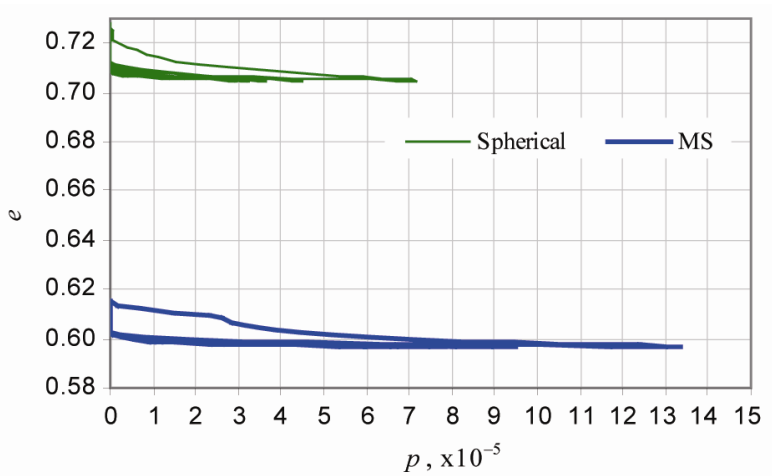

Fig. 11. Variation of the void ratio vs pressure during cyclic loading

After the evaluation of strains obtained by Eq. (7), the updated stress-strain relationship is presented in Fig. 11.

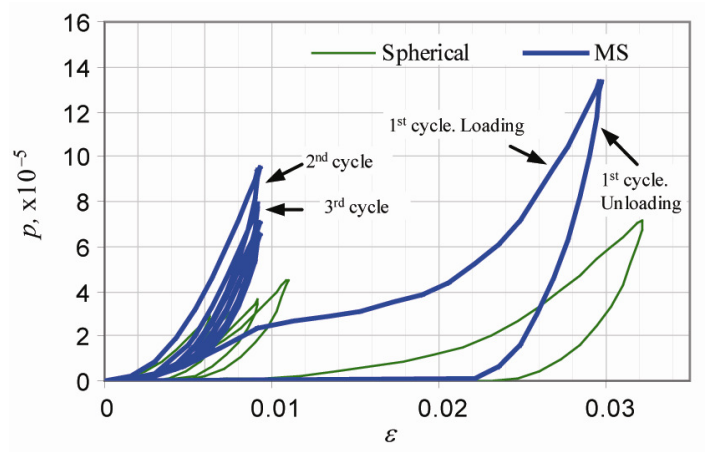

Fig. 12. Axial stress-strain curve of cyclic load for both specimens

Finally, the oedometric elasticity modulus can be obtained on the basis of conventional Eq. (5). In our case, we deal with the tangential modulus which is calculated as a tangent of deformation curve given in Fig. 12. A transformation of loop profiles illustrates a stiffening of the spherical sample material while temporary insignificant relaxation of the MS sample for increased number of cycles.

The variation of the tangential elasticity modulus of two tested samples during the cyclic loading is presented in Fig. 13. Here, the elasticity modulus is scaled with respect to the modulus of a particle.

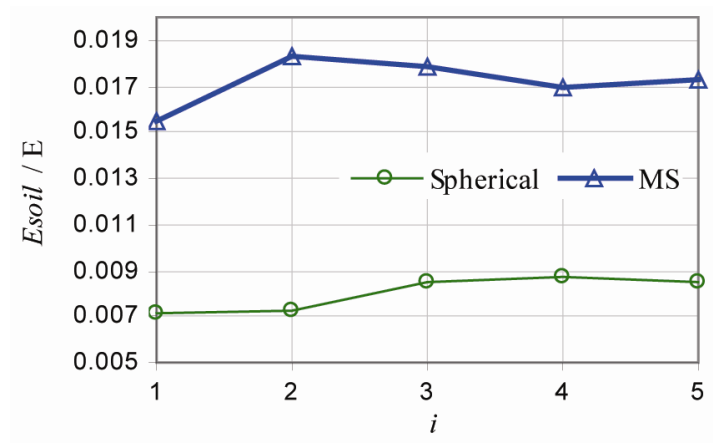

Fig. 13. Variation of relative oedometric elasticity modulus versus loading cycles for S and MS Samples 
The graphs demonstrate that the densification of MS particles practically reached the limit during the second cycle. The further loading indicates small relaxation which may be a reason of the overloading in the second cycle. Yet another reason may be the contribution of the numerical scaling. Densification of S particles is slower and the larger number of cycles is required to reach a stable limit. One can state the general tendency for particle shape (i.e. MS versus S), contribution to stiffening may be characterised by the factor 1.9.

It should be noticed that detailed analysis of the particle overlap demonstrates elastic inter-particle contact behaviour. Therefore proportionality of scaled system is indirectly proved.

\section{Conclusions}

Results of comparison study of deformation behaviour of spherical and multi-spherical particle shape models under cyclic uniaxial compression in the oedometric device may be summarised following:

A relatively simpler model of spherical particles is much more sensitive to their rearrangement of particles during loading-unloading densification. Densification is slow and a higher number of cycles is required to stabilise the deformation behaviour.

More complex, but much more expensive and complicated multi-spherical particle material model showed practically stable behaviour after the first cycle. The obtained elasticity modulus is higher by approximately 1.9 times during the cycle of loading period when compared to the one obtained by material model of spherical particles.

Future research is required, however, to evaluate an influence of friction, optimal number of particle types, and obviously the validation with results of real experiments.

\section{Acknowledgement}

The contribution of co-author Liudas Tumonis was supported by the EU Structural Funds project "Postdoctoral Fellowship Implementation in Lithuania" within the framework of the Measure for Enhancing Mobility of Scholars and Other Researchers and the Promotion of Student Research (VP1-3.1-ŠMM-01) of the Program of Human Resources Development Action Plan.

An equipment and infrastructure of Civil Engineering Scientific Research Centre of Vilnius Gediminas Technical University was employed for investigation.

\section{References}

Allen, M. P.; Tildesley, D. J. 1987. Computer simulation of liquids. Oxford University Press, USA. 408 p.

Amšiejus, J.; Dirgèlienė, N. 2007. Probabilistic assessment of soil shear strength parameters using triaxial test results, The Baltic Journal of Road and Bridge Engineering 2(3): 125-131.

Amšiejus, J.; Dirgèlienė, N.; Norkus, A.; Žilionienė, D. 2009. Evaluation of soil strength parameters via triaxial testing by height versus diameter ratio of sample, The Baltic Journal of Road and Bridge Engineering 4(2): 55-60.
Amšiejus, J; Kačianauskas, R.; Norkus, A.; Tumonis, L. 2010. Investigation of the sand porosity via oedometric testing, The Baltic Journal of Road and Bridge Engineering 5(3): 139-147. http://dx.doi.org/10.3846/bjrbe.2010.20

Antonyuk, S.; Palis, S.; Heinrich, S. 2011. Breakage behaviour of agglomerates and crystals by static loading and impact, Powder Technology 206(1-2): 88-98. http://dx.doi.org/10.1016/j.powtec.2010.02.025

Belevicius, R.; Kačianauskas, R.; Markauskas, D.; Šešok, D. 2011. Packing of polydispersed discs into containers of regular shape, Particulate Science and Technology: An International Journal 29(1): 28-39. http://dx.doi.org/10.1080/02726351.2010.503323

Chen, K.-C.; Lan, J.-Y. 2009. Micromorphic modeling of granular dynamics, International Journal of Solids and Structures 46(6): 1554-1563. http://dx.doi.org/10.1016/j.ijsolstr.2008.11.022

Cundall, P. A.; Strack, O. D. L. 1979. A discrete numerical model for granular assemblies, Géotechnique 29(1): 4765. http://dx.doi.org/10.1680/geot.1979.29.1.47

DEM Solutions. 2009. EDEM v2.2. Edinburgh, UK: DEM Solutions Ltd.

Džiugys, A.; Peters, B. 2001. An approach to simulate the motion of spherical and non-spherical fuel particles in combustion chambers, Granular Matter 3(4): 231-266. http://dx.doi.org/10.1007/PL00010918

Garcia, X.; Latham, J.-P.; Xiang, J.; Harrison, J. P. 2009. A clustered overlapping sphere algorithm to represent real particles in distinct element modelling, Géotechnique 59(9): 779-784. http://dx.doi.org/10.1680/geot.8.T.037

Favier, J. F.; Abbaspour-Fard, M. H.; Kremmer, M.; Raji, A. O. 1999. Shape representation of axisymmetrical, nonspherical particles in discrete element simulation using multi-element model particles, Engineering Computations 16(4): 467-480. http://dx.doi.org/10.1108/02644409910271894

Ferellec, J.-F.; McDowell, G. R. 2010. A method to model realistic particle shape and inertia, Granular Matter 12(5): 459-467. http://dx.doi.org/10.1007/s10035-010-0205-8

ISO 14688-2:2004 Geotechnical investigation and testing. Identification and classification of soil. Part 2: Principles for a classification. International Organization for Standartization, 2004. 14 p.

Höhner, D.; Wirtz, S.; Kruggel-Emden, H.; Scherer, V. 2011. Comparison of the multi-sphere and polyhedral approach to simulate non-spherical particles within the discrete element method: Influence on temporal force evolution for multiple contacts, Powder Technology 208(3): 643656. http://dx.doi.org/10.1016/j.powtec.2011.01.003

Jiang, Y.; Liu, M. 2007a. A brief review of "granular elasticity" Why and how far is sand elastic? The European Physical Journal E - Soft Matter and Biological Physics 22(3): 255260.

Jiang, Y.; Liu, M. 2007b. From elasticity to hypoplasticity: dynamics of granular solids, Physical Review Letters 99(10): 105-501.

http://dx.doi.org/10.1103/PhysRevLett.99.105501

Jiang, Y.; Liu, M. 2009. Granular solid hydrodynamics, Granular Matter 11(3): 139-156.

http://dx.doi.org/10.1007/s10035-009-0137-3

Kačianauskas, R.; Maknickas, A.; Kačeniauskas, A.; Markauskas, D.; Balevičius, R. 2010. Parallel discrete element simulation of polydispersed granular material, Advances in Engineering Software 41(1): 52-63. http://dx.doi.org/10.1016/j.advengsoft.2008.12.004 
Kruggel-Emden, H.; Simsek, E.; Rickelt, S.; Wirtz, S.; Scherer, V. 2007. Review and extension of normal force models for the Discrete Element Method, Powder Technology 171(3): 157-173. http://dx.doi.org/10.1016/j.powtec.2006.10.004

Kruggel-Emden, H.; Rickelt, S.; Wirtz, S; Scherer, V. 2008. A study on the validity of the multi-sphere Discrete Element Method, Powder Technology 188(2): 153-165. http://dx.doi.org/10.1016/j.powtec.2008.04.037

Kruggel-Emden, H.; Stepanek, F.; Munjiza, A. 2010. A study on adjusted contact force laws for accelerated large scale discrete element simulations, Particuology 8(2): 161-175. http://dx.doi.org/10.1016/j.partic.2009.07.006

Luding, S.; Lätzel, M.; Volk, W.; Diebels, S.; Herrmann, H. J. 2001. From discrete simulations to a continuum model, Computer Methods in Applied Mechanics and Engineering 191(1-2): 21-28.

http://dx.doi.org/10.1016/ S0045-7825(01)00242-0

Markauskas, D.; Kačianauskas, R.; Džiugys, A.; Navakas, R. 2010. Investigation of adequacy of multi-sphere approximation of elliptical particles for DEM simulations, Granular Matter 12(1): 107-123. http://dx.doi.org/10.1007/s10035-009-0158-y

Markauskas, D.; Kačianauskas, R. 2011. Investigation of rice grain flow by multi-sphere particle model with rolling resistance, Granular Matter 13(2): 143-148. http://dx.doi.org/10.1007/s10035-010-0196-5

Marketos, G.; Bolton, M. D. 2010. Flat boundaries and their effect on sand testing, International Journal for Numerical and Analytical Methods in Geomechanics 34: 821837.

Oquendo, W. F.; Muñoza, J. D.; Lizcano, A. 2009. Oedometric test, Bauer's law and the micro-macro connection for a dry sand, Computer Physics Communications 180(4): 616-620. http://dx.doi.org/10.1016/j.cpc.2009.01.002

Langston, P. A.; Al-Awamleh, M. A.; Fraige, F. Y.; Asmar, B. N. 2004. Distinct element modelling of nonspherical frictionless particle flow, Chemical Engineering Science 59(2): 425-435. http://dx.doi.org/10.1016/j.ces.2003.10.008

Pournin, L.; Weber, M.; Tsukahara, M.; Ferrez, J.-A.; Ramaioli, M.; Liebling, T. M. 2005. Three-dimensional distinct element simulation of spherocylinder crystallization, Granular Matter 7(2-3): 119-126.

http://dx.doi.org/10.1007/s10035-004-0188-4
Pőschel, T.; Salueña, C.; Schwager, T. 2001. Scaling properties of granular materials, Physical Review 64(1): 14.

Raji, A. O.; Favier, J. F. 2004. Model for the deformation in agricultural and food particulate materials under bulk compressive loading using discrete element method. I: Theory, model development and validation, Journal of Food Engineering 64(3): 359-371.

http://dx.doi.org/10.1016/j.jfoodeng.2003.11.004

Rojek, J.; Zarate, F.; de Saracibar, C. A.; Gilbourne, C.; Verdot, P. 2005. Discrete element modelling and simulation of sand mould manufacture for the lost foam process, International Journal for Numerical Methods in Engineering 62(11): 1421-1441. http://dx.doi.org/10.1002/nme.1221

Tijskens, E.; Rioual, F. 2008. Representing particle shape in Discrete Element Modelling, in Proc. of 4th International Symposium "Reliable Flow of Particulate Solids", 10-12 June, 2008, Tromsø, Norway, 214-219.

Wang, D.; Wang, Y.; Yang, B.; Zhang, W. 2008. Statistical analysis of sand grain/bed collision process recorded by high-speed digital camera, Sedimentology 55(2): 461-470. http://dx.doi.org/10.1111/j.1365-3091.2007.00909.x

Yan, G.; Yu, H.-s.; McDowell, G. 2009. Simulation of granular material behaviour using DEM, Procedia Earth and Planetary Science 1(1): 598-605. http://dx.doi.org/10.1016/j.proeps.2009.09.095

Zalewski, R. 2010. Constitutive model for special granular structures, International Journal of Non-Linear Mechanics 45(3): 279-285. http://dx.doi.org/10.1016/j.ijnonlinmec.2009.11.011

Zhu, H. P.; Zhou, Z. Y.; Yang, R. Y.; Yu, A. B. 2007. Discrete particle simulation of particulate systems: theoretical developments, Chemical Engineering Science 62(13): 33783396. http://dx.doi.org/10.1016/j.ces.2006.12.089

Zhu, H. P.; Zhou, Z. Y.; Yang, R. Y.; Yu, A. B. 2008. Discrete particle simulation of particulate systems: A review of major applications and findings, Chemical Engineering Science 63(23): 5728-5770. http://dx.doi.org/10.1016/j.ces.2008.08.006

Liudas TUMONIS. Received PhD degree in mechanical engineering from Vilnius Gediminas Technical University, Lithuania in 2010. From 2011 he is postdoc at Lithuanian energetics institute. His research interests include the finite element method, the discrete element method and application of other numerical methods in mechanical engineering.

Rimantas KAČIANAUSKAS. Received PhD degree in structural engineering from Vilnius Gediminas Technical University, Lithuania in 1982. He is the Head of the Department of Strength of Materials at Vilnius Gediminas Technical University. His research interests include the finite element method, the discrete element method, structural dynamics, mechanics of materials, fracture mechanics, and coupled problems.

Arnoldas NORKUS. Prof. Dr. Head of Department of Geotechnical Engineering, Vilnius Gediminas Technical University. Research interests: soil mechanics, geotechnical engineering, modelling mechanical properties of soils.

Daiva ŽILIONIENĖ. Doctor of Technological Sciences, Civil Engineering, Vilnius Gediminas Technical University, 2003. A member of Low-Volume Roads Committee in Transportation Research Board (TRB) of the National Academies, USA. Research interests: road design, construction, reconstruction and maintenance, road information systems and traffic safety, low-volume road planning, design, construction, operation and maintenance. 